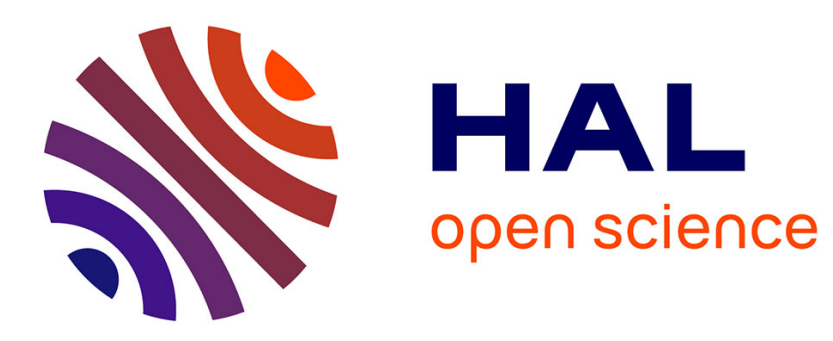

\title{
Ontological approach for product-centric information system interoperability in networked manufacturing enterprises
}

\author{
Angela Tursi, Hervé Panetto, Gérard Morel, Michele Dassisti
}

\section{To cite this version:}

Angela Tursi, Hervé Panetto, Gérard Morel, Michele Dassisti. Ontological approach for productcentric information system interoperability in networked manufacturing enterprises. Annual Reviews in Control, 2009, 33 (2), pp.238-245. 10.1016/j.arcontrol.2009.05.003 . hal-00361394v2

\section{HAL Id: hal-00361394 \\ https://hal.science/hal-00361394v2}

Submitted on 22 Oct 2009

HAL is a multi-disciplinary open access archive for the deposit and dissemination of scientific research documents, whether they are published or not. The documents may come from teaching and research institutions in France or abroad, or from public or private research centers.
L'archive ouverte pluridisciplinaire HAL, est destinée au dépôt et à la diffusion de documents scientifiques de niveau recherche, publiés ou non, émanant des établissements d'enseignement et de recherche français ou étrangers, des laboratoires publics ou privés. 


\title{
ONTOLOGICAL APPROACH FOR PRODUCTS-CENTRIC INFORMATION SYSTEM INTEROPERABILITY IN NETWORKED MANUFACTURING ENTERPRISES
}

\author{
Tursi A. ${ }^{1,2}$, Panetto H. ${ }^{1 *}$, Morel G. ${ }^{1}$, Dassisti M. ${ }^{2}$ \\ ${ }^{1}$ Centre de Recherche en Automatique de Nancy (CRAN - UMR 7039), Nancy-Université, CNRS, France \\ \{angela.tursi, herve.panetto,gerard.morel\}@cran.uhp-nancy.fr \\ ${ }^{2}$ Dipartimento di Ingegneria Meccanica e Gestionale, Politecnico di Bari, Italy \\ m.dassisti@poliba.it
}

\begin{abstract}
Standardisation initiatives (ISO and IEC) try to answer the problem of managing heterogeneous information, scattered within organizations, by formalising the knowledge related to products technical data. While the product is the centred object from which, along its life cycle, all enterprise systems, either inside a single enterprise or between cooperating networked enterprises, have a specific view, we may consider it as active as far as it participates to the decisions making by providing knowledge about itself. This paper proposes a novel approach, postulating that the product, represented by its technical data, may be considered as interoperable per se with the many applications involved in manufacturing enterprises as far as it embeds knowledge about itself, as it stores all its technical data, provided that these are embedded on a common model. The matter of this approach is to formalise of all technical data and concepts contributing to the definition of a Product Ontology, embedded into the product itself and making it interoperable with applications, minimising loss of semantics.
\end{abstract}

Keywords: Enterprise Integration and Networking, Interoperability, Product Data Management, Ontology, IEC 62264, ISO 10303,

\section{INTRODUCTION}

Nowadays, information management is considered as a main requirement for products development in a networked environment. The new communication technologies, such as wireless technologies, RFID (Radio Frequency IDentification), etc., allow, from a technological point of view, to consider products as active mobile objects, embedding their own information structure, used and updated by the various actors during the product lifecycle.

By this way, these products may be considered as systems, like other classical systems, that collaborate for a common objective (development, traceability, etc.). However, it is possible to demonstrate that the properties of such a system are in line with the so- called System of Systems concept (Maier, 1998), in which interoperability is a major concern.

Indeed, a System of Systems ( $\mathrm{SoS}$ ) is a system arising from collaborative functioning of unit systems, each of them being able to work alone in order to perform its own operational mission (INCOSE ${ }^{1}$ ). A SoS is such if it satisfies the following criteria (Maier, 1998):

1. Operational Independence of Elements

2. Managerial Independence of Elements

3. Evolutionary Development

4. Emergent Behaviour

5. Geographical Distribution

\footnotetext{
${ }^{1}$ INCOSE (International Council on Systems Engineering), http://www.incose.org
} 
Based on these characteristics, studies (Morel et al., 2007) try to demonstrate that, in some extent, an enterprise may be considered as a SoS, because it is recursively composed of systems (its elements), and has a particular finality, related to its skill domain, resulting from the execution of enterprise applications. In this paper, we postulate that a product embedding its own knowledge (information) and equipped with communication facilities can be considered as a component element (an active object) of such a SoS. Indeed a product is able to "act independently" (criteria 1,2 ) during its lifecycle if it embeds an information model that gives it the possibility to store data necessary to ensure its existence. The other SoS criteria, related to the enterprise, are not put at fault when one SoS element is an active object.

The main objective of our research activities is then to define the information model necessary to the product to become an active object. With such information, it may be interoperable per se with the many applications involved in manufacturing enterprises and, as far as it embeds knowledge about itself, storing all its technical data, it will be able to act as a common source of understanding between enterprises applications (Tursi et al, 2007).

The paper puts a first step in this direction by endeavouring existing standards related to product technical data modelling for the definition of products information, allowing a non ambiguous model to represent knowledge and concepts, processable by the many enterprise applications adopted in manufacturing environment. A second step will be to formalise this information model as a Product Ontology, thus including domain rules, able to express and share product knowledge among systems. An ontology is an explicit specification of a shared conceptualization (Gruber, 1993), which allows the representation of domain's knowledge. It allows the formalization of the semantics of objects, and then it allows to formalize and to identify the modelling concepts and their dynamic behaviour, in order to express and to share this knowledge.

The shape of the paper is as following: after introducing the concept of active mobile object in section 2, section 3 introduces standards concerned on information interoperability that are used as a base for defining the product ontology; section 4 presents a case study of instantiation of the standards models defining, by a bottom-up approach, the common concepts that will be a base for our product ontology, and finally in section 5 future research activities and conclusions are presented.

\section{PRODUCT AS AN ACTIVE MOBILE OBJECT}

In order to better optimise its performance, heterogeneous enterprise applications, either at business or at manufacturing levels, either inside a single enterprise or among networked enterprises, need to share information and to cooperate. This information may be stored, processed and communicated in different ways by different applications, according to the scopes for which these have been collected and they will be used. Each enterprise application, in fact, uses an information repository, which refers to a Reference Information Model (RIM). A RIM specifies the structure and embeds the semantics of the information treated, in relation to the scope of the application to which it is devoted (Dassisti et al., 2006). However, a problem of misunderstanding when information is exchanged between enterprise applications can occur, due to different view points, for which they have been developed and, consequently, a risk of loss of information semantics may arise when exchanging between heterogeneous systems.

This "Babel tower effect", induced by the heterogeneity of applications, of users and of domains may cause information understanding problems, leading systems to fail at collecting information from different and heterogeneous sources to effectively ensure their local objective. This problem of managing heterogeneous information coming from different systems, in order to achieve a unique comprehension, falls within the umbrella of interoperability problems. Generally speaking, interoperability can be defined as that intrinsic characteristic of a generic entity (organization, system, process, model, ...) allowing its interaction with other entities - to a different extent of simplicity - to cooperate for achieving a common goal within a definite interval of time, while pursuing its own specific goal. Interoperability can defined as the ability of two or more systems or components to exchange information and to use the information that has been exchanged (IEEE, 1990).

In order to manage heterogeneous information, it is mandatory to develop models able to trace all relevant information related to the product lifecycle (design, manufacturing, sales, use and disposal). This information is, in fact, quite often scattered within organizations: it is a matter of the materials adopted, of the applications used to manage technical data (e.g: Product Data Management systems (PDM)), of the applications that manage business data (e.g.: Enterprise Resource Planning (ERP)) and, finally, of the applications that manage manufacturing data (e.g.: Manufacturing Execution Systems (MES)).

Standardisation initiatives, for instance in the frame of ISO (ISO 10303) and IEC (IEC 62264), try to answer this problem by formalising the knowledge related to products technical data: nevertheless this approach is rather prescriptive, because it forces users to translate information from generic concepts to more practical and ad-hoc ones.

This paper postulates that, the product, along its life cycle, is the centred object from which all applications have a specific view. It could then be possible to define a common information model, to support information exchange between the product views and the many applications that interact with them.

This model intends to specify an embedded Product Ontology that may be formed during the product lifecycle by the force of necessity of using it to communicate with the applications. The concept of 
embedding is related to the "pertinence" of the information structure: whenever related to the product information (technical, managerial, operational ...) assumes a local (say embedded) meanly independently of the specific IT application requiring it (ERP, MES, PDM ...). In order to overcome questions pertinent to information exchange and its support, such as loss of information, problems of misunderstanding as well as redundant activities, it is necessary to define an ontology-based information model, to support information exchange between IT applications adopted to control different manufacturing processes and systems.

An ontology provides formal definitions of basic concepts in a domain and the relationships among them in a usually logic-based language (Gruninger and Lee, 2002). It is a specification of a conceptualization of an application domain of interest together with axioms that do constrain the possible interpretations for the defined concepts. There have been, in many different sectors, some efforts examining the use of ontologies in supporting the semantic integration task (e.g. Guo et al., 2003; Katranuschkov et al. 2003; Gehre et al., 2005; Lima et al. 2005; Patil et al., 2005; Terzi, 2005; Terzi, et al. 2007). (Patil et al., 2005) is related to the NIST initiative ${ }^{2}$ on Product Engineering. (Terzi, 2005) has also been implemented in the frame of the PROMISE-PLM European project ${ }^{3}$. However, all these works have been either related to geometry data or have focused their study in the technology rather than to the conceptual view of product data exchange. Aware of the efforts demonstrating the integration of models using ontologies, the matter of the approach, discussed here, is how to formalise such Product Ontology, so it is feasible to embed information into the product and bringing and using them without further misunderstanding. Formalization means to provide a structured model of the information concepts and their semantics. Once the ontology is embedded, it represents a comprehensive structure of all the possible information pertinent to the product and genealogy. As far as the product is processed, the related information can be "engraved" on it, with regards to the embedded ontology. This represents a significant advantage in terms of information retrieval and future use.

In this sense, standards efforts can be taken into account, in term of useful bases for the ontology of the domain. The product may then be considered as active, as far as it participates to the decisions making, providing knowledge about itself.

Through the formalization of this model, the product may be considered as interoperable per se as far as it embeds local information (knowledge about itself), as it stores all its technical data, provided that these are embedded on a common model, providing mappings from and to the enterprise applications (either inside a single enterprise or between networked enterprises) with respect to its life cycle.

\footnotetext{
${ }^{2}$ http://www.mel.nist.gov/msid/pe.htm

${ }^{3} \mathrm{http}: / /$ www.promise-plm.com
}

This paper discusses these ideas and traces a research roadmap on this topic, to explore the possibility to make enterprise interoperable on the basis of productcentred information view.

\section{STANDARDS FOR PRODUCT DATA REPRESENTATION AND EXCHANGE}

The integrated management of all the information regarding the product and its manufacturing is one of the more complex questions that characterize today's environment, defining a sort of "product-centric" or "product-driven" paradigm (Morel et al., 2003). We have studied a comprehensive set of standards related to product data and product lifecycle management (Terzi, 2005) and we have then demonstrated that information interoperability asks for common shared approaches: in fact, interesting standardisation initiatives already exist, such as the IEC 62264 set of standards (IEC 62264, 2002) and the ISO 10303 technical specifications (ISO/TS 10303, 2004. They try to solve the problem of managing heterogeneous information coming from different systems by formalising the knowledge related to products technical data. Both these standards will be here addressed because they are related to Product Data Management at the business and the manufacturing levels of enterprises (B2M, Business to Manufacturing). In the following sub-paragraph a short review will be done of these two standards.

\subsection{IEC 62264 set of standards.}

The IEC 62264 set of standards specify a set of reference models for information exchange to facilitate the integration of business applications and manufacturing control applications, within an enterprise. The full standard is composed by six different parts designed for defining the interfaces between enterprise activities and control activities. Among all its parts, the part 1 specifies the relevant functions within an enterprise and within the control domain of an enterprise, stating which objects are normally exchanged between these domains. The key aspects for integrating the business applications and the manufacturing operations and control applications are the information structures and exchanges, related to the products, managed by activities, applications, processes, resources, and functions.

The boundary between the enterprise manufacturing operations and control domains are signed by models: hierarchy model that describes the levels of functions and domains of control associated within manufacturing organizations; data flow model that describes the functional and data flows within manufacturing organizations; object model that describes the information that may cross the enterprise and control system boundary.

There is a set of eight object models that specifies all concepts for enterprise-control integration: three are

* Corresponding author: Herve.Panetto@cran.uhp-nancy.fr 
related to the resource hierarchy (Personnel, Equipment, Material), the process hierarchy (Process Segments, Product Definition), and to the production (Production Schedule, Production Performance, Capability Definition).

$\mathrm{B}^{2} \mathrm{MML}^{4}$ (Business to Manufacturing Markup Language) is an XML (eXtensible Markup Language) implementation of the IEC 62264 part 1. It consists of a set of XML schemas, developed by the World Batch Forum, written using the World Wide Web Consortium's XML Schema language (XSD) that implements the standardised data models. B2MML is meant to be a common data format to link business enterprise applications (such as ERP systems) with manufacturing enterprise applications (such as MES). In particular, MES functions relate to production monitoring including materials (raw and finished) and resources (equipment and personnel) traceability information.

This standard shows a first effort in determining a model that intends facilitate enterprise applications interoperability.

In order to adopt a common understanding for the manipulation of models, we choose the UML (Unified Modeling Language), and more especially the class diagram formalism, as a common conceptual language for representing the concepts specified in the standard.

\subsection{ISO 10303 Technical specifications}

ISO has been pushing forward the development of standards and models to foster the exchange of information related to goods and services (ISO, 2004). Efforts like ISO 10303 STEP - STandard for the Exchange of Product model data - have tried to deal with the issues of integration and interoperability problem. STEP represents the standard for the computer-interpretable representation of product information and for the exchange of product data. It aims to provide a neutral mechanism capable of describing products throughout their lifecycle. Nowadays, STEP has been recognized as appropriate to help in the integration of manufacturing systems in industries such as automotive, aircraft, shipbuilding, furniture, building and construction, gas and oil.

A significant solution for PDM (Product Data Management) data exchange is the Unified PDM Schema, which is a basic specification for the exchange of administrative product definition data. It has been created by unifying all PDM data between all existing STEP Application Protocols, and allows the exchange of information that is stored in PDM systems. This information typically forms the metadata for any product. In order to deal with the increasing demands on product models exchange, the standard has specified a set of STEP reusable modules related to PDM. These modules are now published as technical specifications (TS) and concern all related information attached or

\footnotetext{
${ }^{4}$ B2MML (Business to Manufacturing Markup Language), http://www.wbf.org
}

describing products technical data such as product structure, configuration control, persons and organisations, etc. PDM systems maintain a single copy of the product master data in a secure vault; the data are then distributed to those departments requiring them: modified, updated design data are then resaved in the vault. Data integration ensures that the information describing product design, manufacturing and life cycle support is defined only once; STEP data integration eliminates redundancy and the problems caused by redundant information.

STEP uses the EXPRESS language for describing data type, constraints on data type and relationship between data type. However, Application Protocols are required to contain a representation of the information in both EXPRESS and EXPRESS-G. EXPRESS-G is a diagramming technique supporting a subset of the EXPRESS language.

In this case, we also use the UML Class Diagram formalism as a common conceptual language for specifying the concepts specified in STEP PDM.

\section{A CASE STUDY}

The STEP PDM Schema is a reference information model for the exchange of a central, common subset of the data being managed within a PDM system. A PDM system is able to integrate and manage all applications, information and processes that define a product during its lifecycle, from design to manufacture, and to enduser support (Liu and Xu, 2001). This means that typical product-related information includes geometry, engineering drawings, project plans, part files, assembly diagrams, product specifications, numerical control machine-tool programs, analysis results, correspondence, bills of material, engineering change orders, and many more.

However, it is possible to find some of these information scattered also in the IEC 62264 models. For the sake of simplicity, we will now demonstrate this only by defining some mappings between the PDM schemas and the IEC 62264 material model. Of course, the current work is ongoing taking into account all models.

The IEC 62264 Material Model defines the actual materials, material definitions, and information about classes of material. In this model, material means not only raw materials but also consumables, parts and all other products needed for the production. Material information includes the inventory of raw, finished, and intermediate materials. Material classes are defined to organise materials. A Material definition is a means to describe goods with similar characteristics. A Material Lot object identifies a specific amount of material, countable or weighable, and it has specific properties (Fig. 1).

In order to verify that the same information is modelled in different way by the two standards, we have denormalised and conceptualised PDM STEP Schema and IEC 62264 models and represented them using the UML class diagram notation. In this way, it is possible

* Corresponding author: Herve.Panetto@cran.uhp-nancy.fr 
to have a common minimum denominator which allows the matching and the mapping between the two standards.

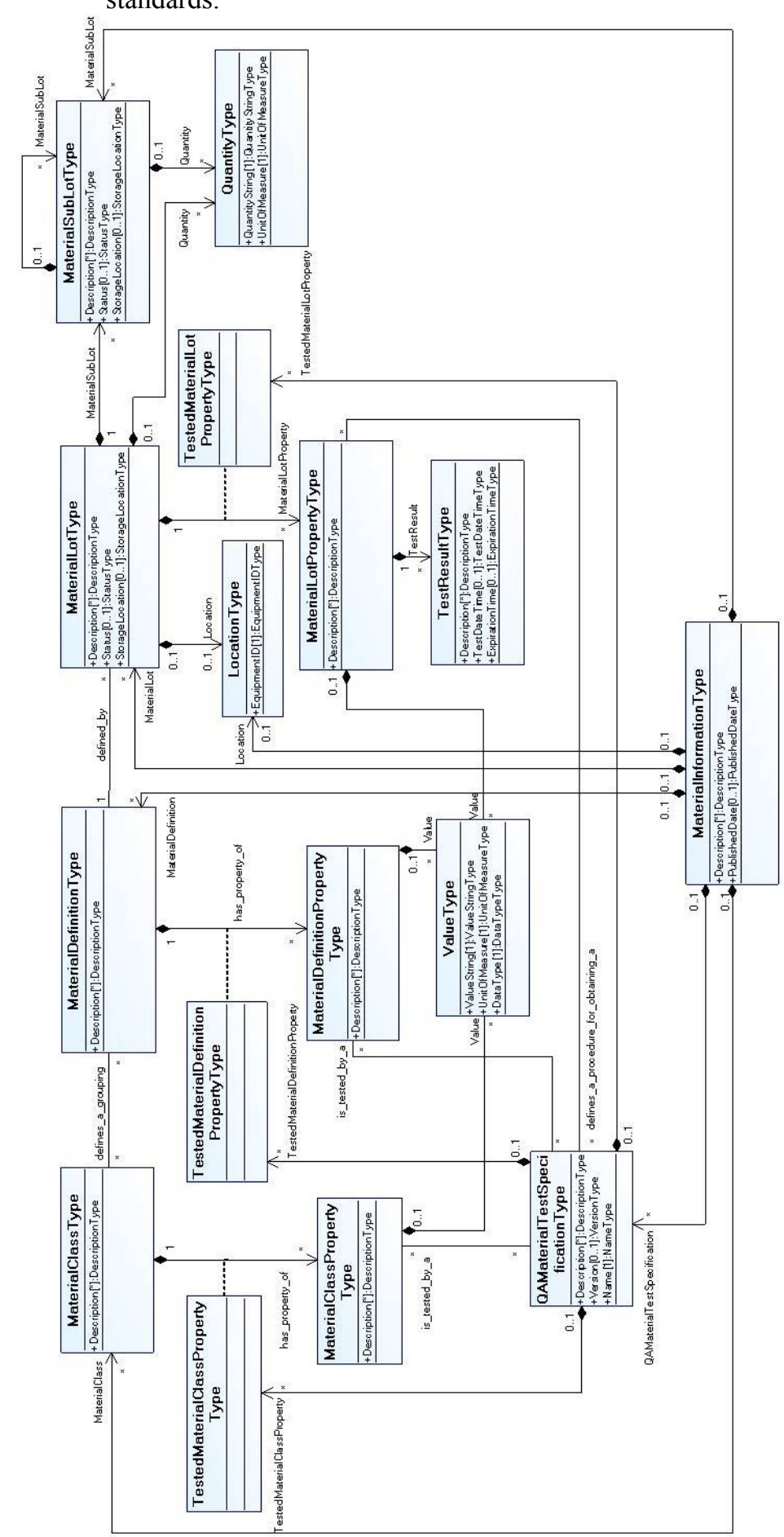

Fig. 1 The conceptualised IEC 62264 Material Model

The following step has been the instantiation of the standards models based on a real production system. Just to provide a more familiar example of real production system, we refer to a simple test case made between two facilities. The proposed case study concerns the design and the production of a product. It is based on a set of enterprise systems, distributed on two production sites, one in Italy and one in France. The product is conceived and designed in the Department of Mechanical and Management
Engineering of the Politecnico di Bari, in Bari, Italy. The definition of product is driven by market or by customer requirements and forecasting. Technical and geometrical information, joined to business information, such as the required quantity of pieces, are stored in a memory chip (a RFID), and structured in the information model that implements the Product Ontology.

This digital product is sent to the Atelier InterÉtablissements de Productique Lorrain (AIPLPRIMECA) of the Nancy-University, France.

AIPL has to manufacture the product on the base of information drawn from the Product Ontology, retrieved from the chip. In this industrial production system, it is possible to manufacture 4 types of base part from a product family and then assemble them in order to compose 6 types of product (Fig.2).

At the end of production process, the manufactured product will be sent to DIMeG in oder to be delivered to the customer.

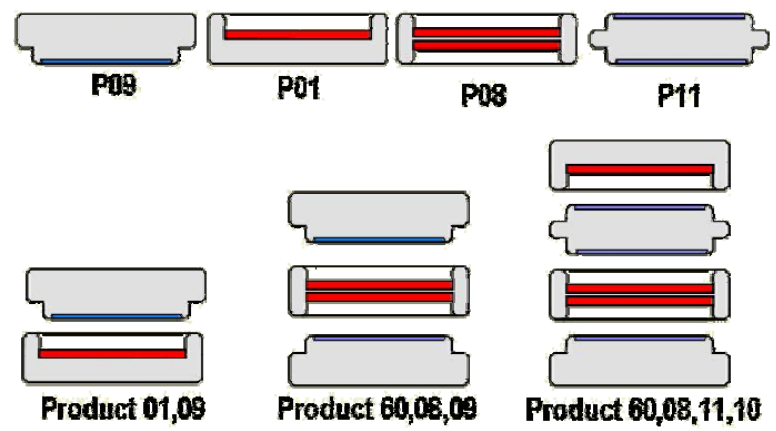

Fig. 2. Parts and some products produced at the AIPL

Each enterprise of this case study is equipped with its enterprise systems (i.e. Windchill PDM and SAP R/3 for DIMeG or DS SmarTeam and Sage X3 for AIPL), dedicated to specific tasks (engineering tasks or manufacturing ones) and provided by a particular vendor. In this product-centric information system, these heterogeneous applications have to interoperate with the product, in order to store and to draw the pertinent product information.

As previously mentioned, to support information exchange between the product and the many applications that interact with him, it is necessary to define a common information model, which intends to specify an embedded Product Ontology. This common information model can be defined starting from IEC 62264 models and the ISO 10303 technical specifications ones. Both these standards are related to product data management at the business and the manufacturing levels of enterprises (B2M).

From the standards analysis, it's possible to state that Material Model, Process Segments Model and Production Schedule Model epitomize the product information during the first steps of the process, during the product definition and production planning phases, carried out at the DIMeG. Some ISO 10303 TS standard concepts will be integrated in this stage. Material, Equipment and Personnel Model, Production Schedule Model, Capability Definition Model, instead, 
epitomize the product information during the product manufacturing phase carried out at the AIPL.

The bill of material (BOM) is one of the crucial product technical data in the production management domain as well as in the information technology that supports it ( $\mathrm{Xu}$ et al, 2008): the BOM represents the base issue of integrating product design system with production planning system. The STEP PDM Schema supports hierarchical product structures representing assemblies and the constituents of those assemblies, as shown in figure 3: this product structure corresponds to the traditional engineering and manufacturing bill of material indentured parts list.

The Assembly_component_relationship class represents the general relationship between two parts, one a definition of a component and the other a definition of the parent assembly. This entity is typically instantiated as the subtype Next_assembly_usage, which represents an unique individual occurrence of the component as used within the parent assembly. The subtype Promissory_usage, instead, represents the usage occurrence of a component within a higher-level assembly that is not the immediate parent. The subtype Component_upper_level_identification identifies a component of an assembly with respect to an upper level in the assembly structure.
The Assembly_component_relationship is established between two instances of Product_view_definition: the relating view of Product_version of assembly and the related one of the Product_version which plays the role of component. A Product_view_definition is a collector of the properties that characterize the Product_version in the initial_context and possibly additional_contexts. A Product_version is a revision or a collector of the definitions of the revision of Product.

An Assembly_component_relationship defines the quantity of the usage of the component in an assembly. This part of STEP PDM represents the so called Engineering BOM (EBOM). The EBOM lists items according to their relationships with parent products as represented on assembly drawings. Thus, EBOM just represents the product structure from the engineering point of view, not from the manufacturing viewpoint, and it cannot be directly used in the material requirements planning (MRP) system, generally a component of an Enterprise Resource Planning system (ERP). From a B2M interoperability point of view, the MES needs a manufacturing BOM (MBOM) to schedule, in real time, the different work in progress (WIP) orders.

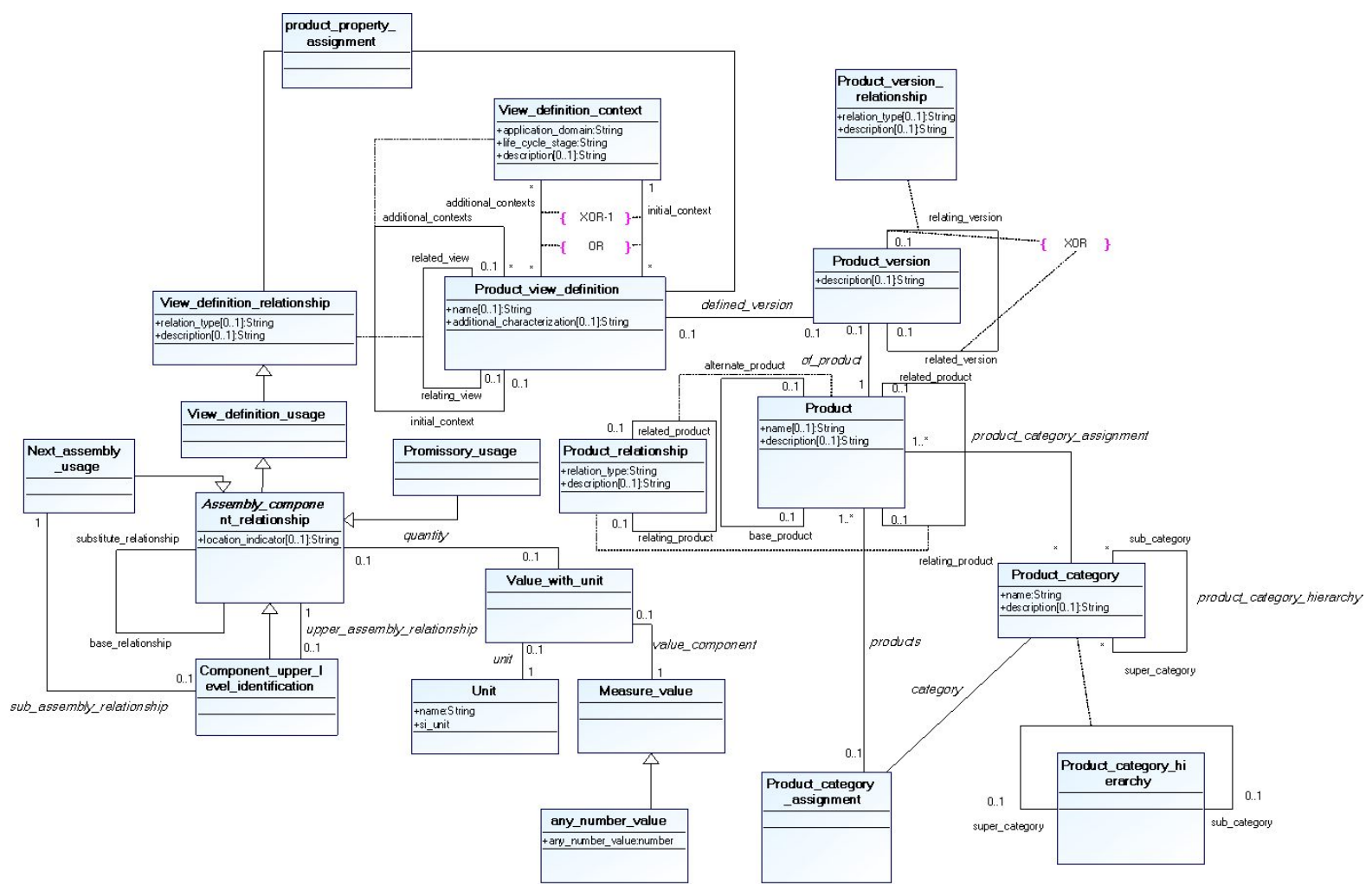

Fig. 3. A conceptualized model of the BOM as based on STEP PDM

The MBOM represents the assembly building-up the way a product is manufactured. The MBOM is generally generated with human intervention based on EBOM and complementing some manufacturing information from the bill of process (BOP).
Thus, one of the key problem of integrating product design system with production planning system is the transformation of engineering $\mathrm{BOM}$ into manufacturing BOM (Xu et al, 2008).

These considerations allow understanding why and how the Product Ontology can be useful for making 
interoperable enterprise applications: through a common information model embedded on the product, which stores product data and information, engineering and manufacturing ones, it will be possible to support information exchange between the many applications that interact with the different product views.

In this paper we focus mainly on the proof of concepts regarding the definition of mappings between both standards by instantiating the IEC 62264 Material Model and the corresponding STEP PDM modules models on a few parts. (Fig. 4, 5).

The figures 4 and 5 show how information related to product properties, such as diameter for example, is defined in both models, even if they are represented in a different way. Indeed, in STEP PDM modules (Fig. 4), the P09 is a product, which is member of $P X X$ family. It is possible to assign diameter property to P09 through the class-relationship assigned_diameter, which is linked to the numerical value through the representation concept. However, we observe that it is not possible to distinguish the definition of a concept for an entity from the value that it assumes. In the same way, in the IEC 62264 (Fig. 5), we note that the diameter concept is defined for Pxx class: P09 part belongs to $P x x$ class, consequently it has a diameter, but it may have also other specific characteristics. Finally, the value of P09 diameter is specified as property of a precise P09 lot.
In order to demonstrate that the models describe the same information, our approach is based, firstly, on a syntactical analysis whose aim is to compare the instances defined in both models and then based on semantics analysis, studying properties of the shared objects. The result of the syntactical analysis is presented in the Table 1. Finally, the semantics analysis suggests the possibility to do a mapping between the instantiated concepts. However each relation between different concepts can be studied and it is possible to try semantic correspondences between them (Baïna, 2006) in order to compare the contained information. Different cases can occur: equivalence, represented by $\equiv$ symbol (same definition for concepts semantics in the two standards), inclusion, represented by $\subset$ symbol (a semantic concept includes the other one), and intersection, represented by $\cap$ symbol, (the concepts intersection defines the common sense of the two concepts). This will be the next step in our approach towards a common model, embedded into the products, which store all technical data along its life cycle: this represents the starting point for the development of our Product Ontology.

This case study then shows how ISO 10303 and IEC 62264 initiatives formalise the knowledge related to products technical data and, thus, they are useful to define the information model that can allow to consider the product as an active object: other standardisation initiatives may be considered in order to have a full Member of:Product relationship relation_bye S ring=Membership description Sting $=P 09$ belongs to Part group

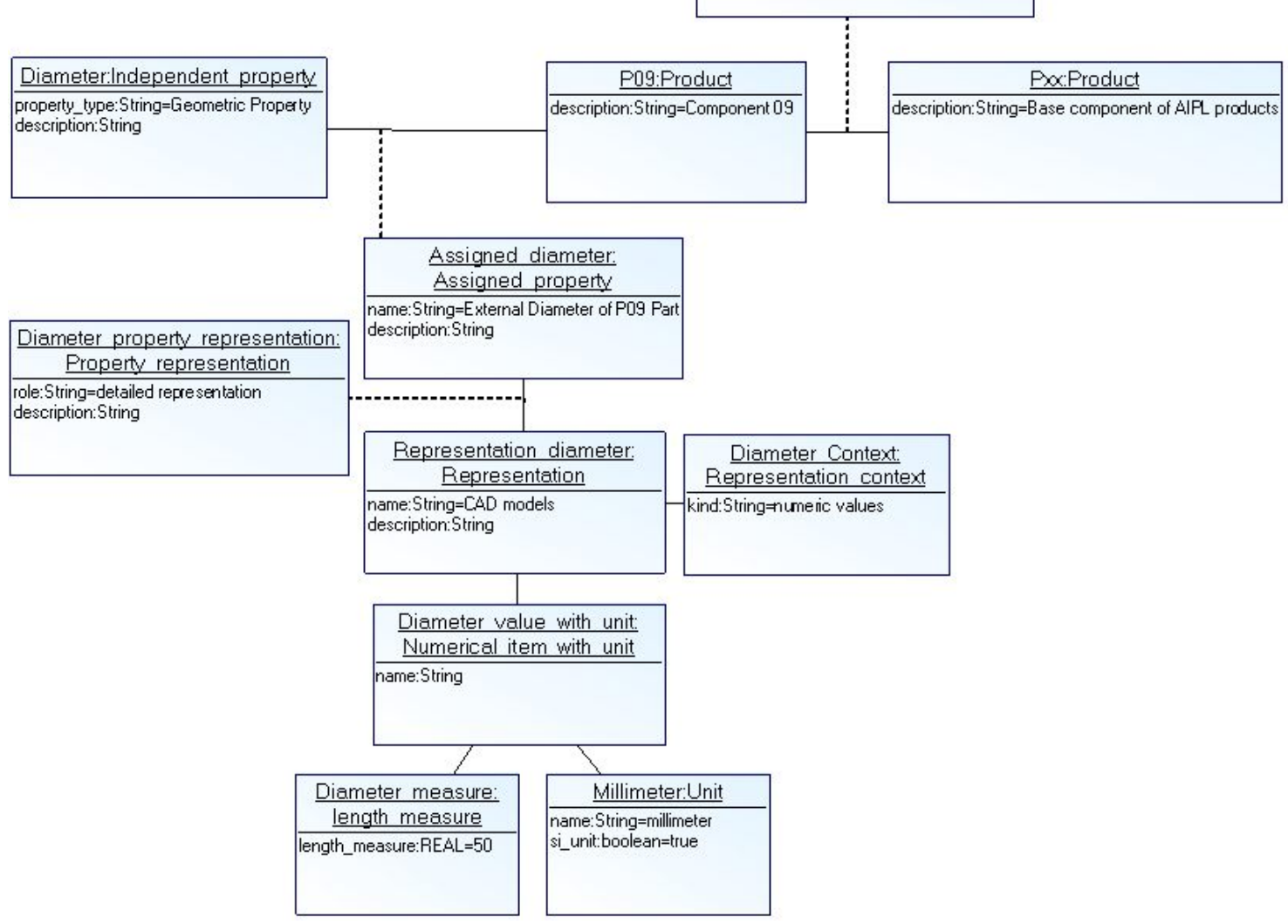

Fig. 4 An extract of the instantiated STEP PDM modules. 


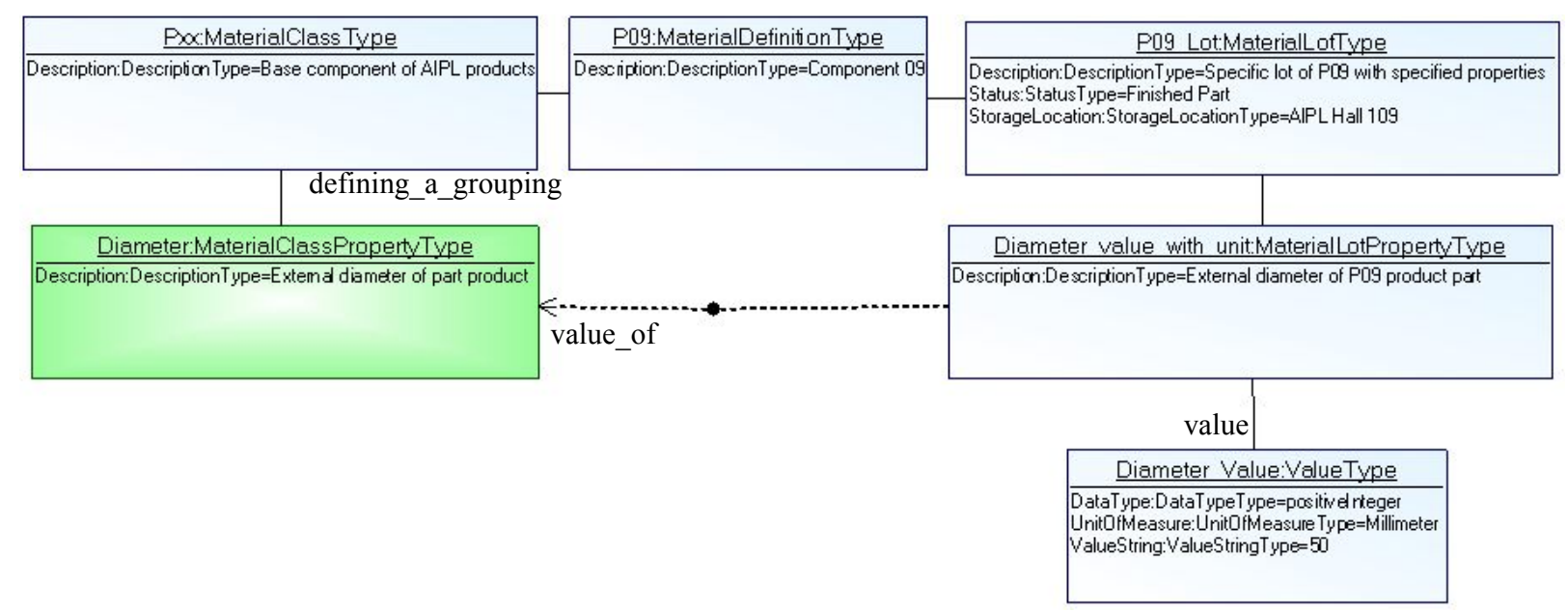

Fig. 5 An extract of the instantiated IEC 62264 Material Model.

Table 1 Syntactical Analysis of concepts

\begin{tabular}{|l|l|l|}
\hline AIPL objects & STEP PDM modules concepts & IEC 62264 concepts \\
\hline Pxx & Pxx: Product & Pxx: MaterialClassType \\
\hline P09 & P09: Product & $\begin{array}{l}\text { P09: MaterialDefinitionType } \\
\text { P09_Lot: MaterialLotType }\end{array}$ \\
\hline Diameter & Diameter: Independent_property & Diameter: MaterialClassPropertyType \\
\hline Diameter_value_with_unit & $\begin{array}{l}\text { Diameter_value_with_unit: } \\
\text { Numerical_item_with_unit }\end{array}$ & $\begin{array}{l}\text { Diameter_value_with_unit: } \\
\text { MaterialLotPropertyType }\end{array}$ \\
\hline
\end{tabular}

model that stores all technical data along the product lifecycle. For analysing the semantics relationships between both concepts, we choose the First Order Logic (FOL) to express predicates formalising concepts of models in order to define, precisely, the mapping between them.

From the syntactical analysis (Table 1), we deduce one or more FOL predicates (1), (2), (3), (4) (Table 2). Each of them formalises mapping between STEP PDM concepts and IEC 62264 ones represented by a DLite description logic (Calvanese et al, 2002).

Finally, we have started the formal verification of these mapping rules through Protégés, a suite of tools to construct domain ontology, by applying skill-based axioms through an inference engine and using it with knowledge-based applications.

\section{CONCLUSIONS AND FUTURE RESEARCH}

Starting from the consideration that the product is the common added value, for which each part of the organization works, and it is the common element perceived in the same way by all manufacturing operators, we have postulate that it is possible to consider the product as an interoperable system per se, as far as it embeds knowledge about itself as it stores all its technical data. This information can be structured in a common formal model, including domain rules, which is able to provide mappings from and to the enterprise applications information, either inside a

${ }^{5}$ protege.stanford.edu

* Corresponding author: Herve.Panetto@cran.uhp-nancy.fr single enterprise or between networked enterprises, with respect to its life cycle.

The matter of the proposed bottom-up approach is then the formalisation of knowledge and skill around products and semantics of standard modelling concepts, for making interoperable enterprise applications related to products views. Our current work is, based on these concepts mapping coming from standards, the definition of a Product Ontology to contribute to an interoperability solution between active mobile objects and enterprise applications that will manage them.

\section{Table 2 FOL Predicates}

\begin{tabular}{|c|c|}
\hline $\begin{array}{c}\text { Product(Pxx) } \wedge \text { Product }(\text { P09) } \wedge \\
\text { Product_relationship }(\text { Member_of }) \wedge \\
\text { Member_of }(\text { Pxx, P09 }) \wedge \\
\text { Member_of.relation_type="Membership" } \\
\Rightarrow \text { MaterialClassType }(\text { Pxx }) \wedge \text { MaterialDefinitionType }(\text { P09) } \\
\wedge \text { defines_a_grouping }(\text { Pxx, P09) }\end{array}$ & (1) \\
\hline \multicolumn{2}{|l|}{$\begin{array}{l}\text { Product } \supset \text { MaterialClassType } \\
\text { Product } \equiv \text { MaterialDefinitionType }\end{array}$} \\
\hline $\begin{array}{c}\text { Independent_property }(\text { Diameter }) \wedge \text { Product }(\mathrm{P} 09) \wedge \\
\text { Assigned_property }(\text { Assigned_diameter }) \wedge \\
\text { Assigned_diameter(Diameter, P09) } \\
\Rightarrow \text { MaterialClassType }(\text { Pxx }) \wedge \text { MaterialDefinitionType }(\mathrm{P} 09) \\
\wedge \text { defines_a_grouping }(\text { Pxx, P09) } \wedge \\
\text { MaterialClassPropertyType }(\text { Diameter }) \wedge \\
\text { MaterialClassProperty }(\text { Pxx, Diameter }) \\
\end{array}$ & (2) \\
\hline $\begin{array}{l}\text { Independent_property } \equiv \text { MaterialClassPropertyType } \\
\text { Numerical_item_with_unit } \equiv \text { MaterialLotPropertyType }\end{array}$ & \\
\hline
\end{tabular}




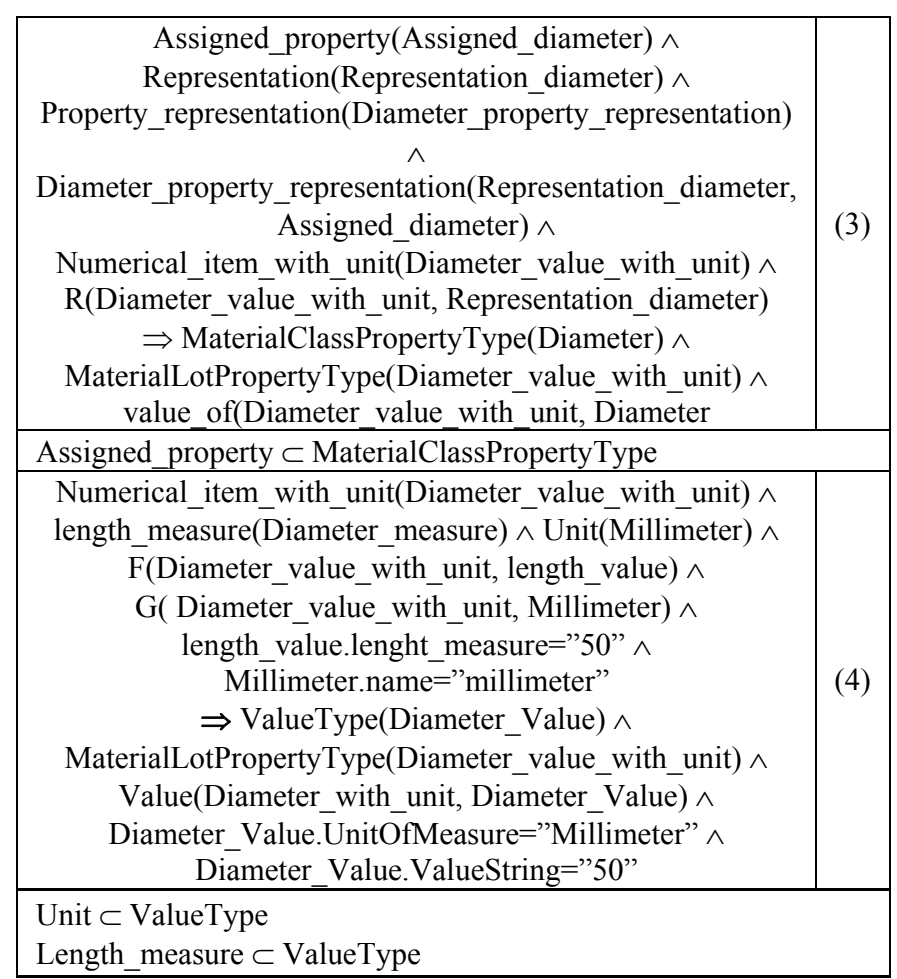

\section{REFERENCES}

Baïna, S. (2006). Interoperabilite Dirigée par les Modèles : Une Approche Orientée Produit pour l'interopérabilité des systèmes d'entreprise. $\mathrm{PhD}$ Université Henri Poincaré, Nancy I, France. December (in french).

Calvanese D., De Giacomo G., and Lenzerini M. (2002). Description logics for information integration. In Computational Logic: From Logic Programming into the Future, Lecture Notes in Computer Science. Springer Verlag..

Dassisti M., Panetto H., Tursi A. (2006). Productdriven Enterprise Interoperability for Manufacturing Systems Integration. Proceedings of the BPM2006 Business Process Management Workshops. 2nd ENEI Workshop, Vienna, Austria, September, LNCS 4103, 249-260. Springer Verlag

IEC 62264 Enterprise-control system integration, Part 1. Models and terminology, Part 2: Model object attributes. ISO/IEC, 2002, Geneva.

IEEE (1990), Standard Computer Dictionary- A Compilation of IEEE Standard Computer Glossaries. NY. 610-1990. ISBN: 1559370793

ISO/TS 10303 STEP modules related to Product Data Management. Industrial automation systems and integration - Product data representation and exchange, 2004, Geneva.

Gehre A., Katranuschkov P., Stankovski V., Scherer R.J. (2005), Towards semantic interoperability in virtual organisations, In: Proc. 22nd Conference of Information Technology in Construction, cibW78, Dresden, Germany. July 18-21.

Gruber T.R. (1993). Toward principles for the design of ontologies used for knowledge sharing. In Formal Ontology in Conceptual Analysis and
Knowledge Representation (N. Guarino and R. Poli, eds.), Kluwer Academic Publishers.

Gruninger M., Lee J. (2002). Ontology — applications and design, In: Communications of the ACM 45/2, 39-41

Guo M., Li S., Dong J., Fu X., Hu Y., Yin Q. (2003). Ontology-based product data integration, In: Proc. 17th International Conference on Advanced Information Networking and Applications; ISBN 0-7695-1906-7, 530-533.

Katranuschkov P., Gehre A., Scherer R. (2003), An ontology framework to access IFC model data, In: ITcon; 8, 413-437

Lima C., Silva C.F., Sousa P., Pimentao J.P. (2005), Interoperability among semantic resources in construction: is it feasible?, In: Proc. 22nd Conference of Information Technology in Construction, cibW78, Dresden, Germany. July 18-21

Liu D.T., Xu X.W. (2001). A review of web-based product data management systems. In: Computer In Industry; 44, 251-262

Maier M.W. (1998). Architecting Principles for Systems-of-Systems, In: Systems Engineering, 1/4, 267-284.

Morel G., Panetto H., Zaremba M.B., Mayer F. (2003). Manufacturing Enterprise Control and Management System Engineering: paradigms and open issues. In: IFAC Annual Reviews in Control. 27/2, 199-209, Elsevier

Morel G., Panetto H., Mayer F., Auzelle J.P. (2007). System of enterprise-Systems integration issues : an engineering perspective. Invited plenary paper. IFAC Cost Effective Automation in Networked Product Development and Manufacturing, October 2 - 5, Monterrey, Mexico, IFAC Papersonline.

Patil L., Dutta D., Sriram R. (2005), Ontology-based exchange of product data semantics, In: IEEE Transactions of Automation Science and Engineering ; 2, 213-225.

Terzi, S. (2005). Elements of Product Lifecycle Management: Definitions, Open Issues and Reference Models. PhD - University Henri Poincaré Nancy I and Politecnico di Milano, May

Terzi S., Panetto H., Morel G., Garetti M. (2007). A holonic metamodel for product lifecycle management. International Journal of Product Lifecycle Management, 2/3, 253-289, Inderscience, December, ISBN 1743-5110

Tursi A., Panetto H., Morel G., Dassisti M. (2007). "Ontology-based products information interoperability in networked manufacturing enterprises". IFAC Cost Effective Automation in Networked Product Development and Manufacturing, October 2 - 5, Monterrey, Mexico, IFAC Papersonline.

$\mathrm{Xu}$ H.C., Xu X.F.. He T. (2008). Research on Transformation Engineering BOM into Manufacturing BOM Based on BOP, Applied Mechanics and Materials. Special issue on eEngineering \& Digital Enterprise Technology. 1012, 99-103 